\title{
Robust extraction of baseline signal of atmospheric trace species using local regression
}

\author{
A. F. Ruckstuhl ${ }^{1}$, S. Henne ${ }^{2}$, S. Reimann ${ }^{2}$, M. Steinbacher ${ }^{2}$, M. K. Vollmer ${ }^{2}$, S. O’Doherty ${ }^{3}$, B. Buchmann ${ }^{2}$, and \\ C. Hueglin ${ }^{2}$ \\ ${ }^{1}$ Institute for Data Analysis and Process Design, Zurich University of Applied Sciences, Winterthur, Switzerland \\ ${ }^{2}$ Empa, Swiss Federal Laboratories for Materials Science and Technology, Laboratory for Air Pollution \\ and Environmental Technology, Dübendorf, Switzerland \\ ${ }^{3}$ Atmospheric Chemistry Research Group, School of Chemistry, University of Bristol, Bristol, UK
}

Correspondence to: C. Hueglin (christoph.hueglin@empa.ch)

Received: 13 October 2010 - Published in Atmos. Meas. Tech. Discuss.: 7 December 2010

Revised: 24 September 2012 - Accepted: 2 October 2012 - Published: 2 November 2012

\begin{abstract}
The identification of atmospheric trace species measurements that are representative of well-mixed background air masses is required for monitoring atmospheric composition change at background sites. We present a statistical method based on robust local regression that is well suited for the selection of background measurements and the estimation of associated baseline curves. The bootstrap technique is applied to calculate the uncertainty in the resulting baseline curve. The non-parametric nature of the proposed approach makes it a very flexible data filtering method. Application to carbon monoxide (CO) measured from 1996 to 2009 at the high-alpine site Jungfraujoch (Switzerland, $3580 \mathrm{~m}$ a.s.1.), and to measurements of 1,1-difluoroethane (HFC-152a) from Jungfraujoch (2000 to 2009) and Mace Head (Ireland, 1995 to 2009) demonstrates the feasibility and usefulness of the proposed approach.

The determined average annual change of $\mathrm{CO}$ at Jungfraujoch for the 1996 to 2009 period as estimated from filtered annual mean $\mathrm{CO}$ concentrations is $-2.2 \pm 1.1 \mathrm{ppb} \mathrm{yr}^{-1}$. For comparison, the linear trend of unfiltered $\mathrm{CO}$ measurements at Jungfraujoch for this time period is $-2.9 \pm 1.3 \mathrm{ppb} \mathrm{yr}^{-1}$.
\end{abstract}

\section{Introduction}

Background monitoring sites are the locations for observing the composition of the clean and remote atmosphere and for detection of long-term changes and trends in important atmospheric trace species. However, many background moni- toring sites are frequently affected by air masses that are influenced by local or regional emissions or air masses that are representing certain atmospheric layers. Air samples taken at these locations are temporarily not representative of wellmixed background air. Hence, data filtering is often an essential part of the analysis of data from those sites. For example, data filtering was applied for trend estimations (Thoning et al., 1989; Novelli et al., 1998; Schuepbach et al., 2001; Novelli et al., 2003; Zellweger et al., 2009), for evaluation of source regions and corresponding emission estimates (Prinn et al., 2001; Cox et al., 2005; Reimann et al., 2005; Greally et al., 2007), as well as for modeling of long-range transport of trace gases (Ryall et al., 1998; Balzani Lööv et al., 2008).

Methods for identification of background measurements are often based on chemical parameters (trace gas concentrations or ratio of trace gases; e.g. Carpenter et al., 2000; Zanis et al., 2007) or take advantage of the knowledge on the transport processes of polluted air masses to the background site (meteorological filters). Meteorological filters have been applied in a number of studies utilizing data from the Swiss high-alpine site Jungfraujoch (JFJ), $3580 \mathrm{~m}$ a.s.1. (Forrer et al., 2000; Zellweger et al., 2003; Henne et al., 2005) for discrimination between disturbed and undisturbed free tropospheric air. In Zellweger et al. (2003), measurements that were identified as being influenced by föhn events (dry down-slope winds in the lee of the Alps), synoptical lifting, or thermally induced vertical transport were excluded from further analysis. Another meteorological data filtering approach is by evaluation of the air mass origin by analysis of 
back trajectories (Derwent et al., 1998; Balzani Lööv et al., 2008), or by utilization of Lagrangian particle dispersion models (Ryall et al., 2001; Hirdman et al., 2010).

Statistical methods are an alternative to the application of chemical parameters and meteorological filters. In contrast to these approaches, statistical methods do not have to be adapted to the conditions at individual measurement sites and can therefore be applied generally making background data of various stations easier to compare. Common statistical methods rely on the identification of measurements that deviate from a smooth curve fit to the data (Novelli et al., 1998; O’Doherty et al., 2001). For example, Novelli et al. (1998) fitted a second-order polynomial plus the sum of four harmonics to daily carbon monoxide ( $\mathrm{CO}$ ) data from the NOAA/CMDL network and applied two low-pass filters to the model residuals. Measurements with large distance to the smoothed curve (defined as the sum of the parametric model fit and the smoothed residuals) were considered as outliers and flagged. The routine was then iteratively applied without the flagged measurements until no additional outliers were identified. In a subsequent study, a modified version of this method was applied (Novelli et al., 2003). In contrast to the earlier method, the model residuals were converted to the frequency domain with a Fourier transform algorithm and filtered by a low-pass and a high-pass filter. The filtered residuals were then transformed back into the time domain and added to the fitted function resulting in the desired smooth curve.

Another statistical method for identification of background measurements was used in several studies from the Global Atmospheric Gases Experiment/Advanced Global Atmospheric Gases Experiment (GAGE/AGAGE) (see e.g. Simmonds et al. (2001)). This approach is based on a threestep procedure and is described in detail by O'Doherty et al. (2001). In brief, the pollution events on a selected day are first identified by applying a second-order polynomial to the daily minima over the time period from 60 days before and 60 days after the selected day. The polynomial fit is then subtracted from the data, and the variability $\sigma$ of the residuals is estimated using only the data that are smaller than the median of the residual distribution. All measurements in the middle day of the 121-day period with residuals exceeding $3 \sigma$ are flagged as being "polluted". In a next step, the complete cycle of flagging data is repeated except that all data points that were marked in the previous cycle are excluded. At the end of this step, measurements between $2 \sigma$ and $3 \sigma$ above the median of the residuals are marked as "possibly polluted". In a final third step, all data points that are marked as "possibly polluted" are also labeled "polluted" if they are immediately adjacent to a polluted data point.

At sites where non-background conditions regularly and often prevail during certain meteorological conditions, purely statistical methods should be used with caution, e.g. when pollution advection from a known nearby source or from the polluted boundary layer can be determined by wind direction and/or time of the day. At such sites statistical methods might tend to wrongly classify measurements during polluted conditions as background observations leading to a bias in the corresponding baseline estimation. Whenever possible, a meteorological filtering of the data should be applied prior to the application of statistical methods. Examples of subsequent use of meteorological and statistical filtering are the publications by Thoning et al. (1989) and Henne et al. (2008). Thoning et al. (1989) applied and compared different selection methods based on daytime and short-term variability of carbon dioxide $\left(\mathrm{CO}_{2}\right)$ at Mauna Loa, Hawaii, to identify data that are influenced by local phenomena and not representative of well-mixed background air. Then, additional statistical filtering similar to the method used by Novelli et al. (2003) was done for removal of remaining shortterm variability in the data.

In this study, a novel statistical approach for extracting background concentrations from measurements is presented. It is based on robust local regression (Cleveland, 1979) and is called REBS (robust extraction of baseline signal). It is a modified version of a technique that was called RBE and developed for baseline removal from chemical analytical spectra (Ruckstuhl et al., 2001). A difference to the RBE technique is the estimation procedure for the scale parameter $\sigma$ of the measurement error. Here we either use only the negative residuals, which is similar to the method by O'Doherty et al. (2001), or preferably only the residuals below the mode of the residual distribution. The precision of the measuring instrument can be considered as a lower bound for the estimate of the scale parameter.

In the next section, the REBS method will be introduced in detail. The proposed method can easily be applied at any background site to time series of trace species without significant surface sinks and latitudinal concentration gradients as discussed in Sect. 5. This is demonstrated by applications to the long-term $\mathrm{CO}$ measurements from Jungfraujoch and to measurements of 1,1-difluoroethane (HFC-152a) from Jungfraujoch, Switzerland, and Mace Head, Ireland. The results are compared with those from the data filtering and baseline fitting technique applied by Novelli et al. (2003) and the GAGE/AGAGE approach for flagging background measurements (O'Doherty et al., 2001). The REBS algorithm is implemented in the function rfbaseline of the IDPmisc package (Ruckstuhl et al., 2009) of the statistical software environment R (R Development Core Team, 2009) and can be downloaded from a CRAN server or received from the authors. Note that the current version of the REBS function in IDPmisc does not include the uncertainty estimation using the bootstrap method as described below. 


\section{Robust extraction of baseline signal}

\subsection{The REBS technique}

In this section, we introduce a statistical approach for extracting background concentrations from trace gas measurements. The presented approach is a modified version of the robust baseline estimation (RBE) technique that was developed for baseline removal from chemical analytical spectra (Ruckstuhl et al., 2001).

We can consider the observed concentrations $Y\left(t_{i}\right)$ to be defined by

$Y\left(t_{i}\right)=g\left(t_{i}\right)+m\left(t_{i}\right)+E_{i}$,

where $g\left(t_{i}\right)$ is the background concentration and $m\left(t_{i}\right)$ is the contribution of regionally polluted air masses at times $t_{i}$ (called regional signal henceforth). The measurement errors $E_{i}$ are assumed to be independent and Gaussian-distributed with mean 0 and variance $\sigma^{2}$. If the regional signal $m\left(t_{i}\right)$ is zero in a time period around $t_{\circ}$, the baseline signal $g\left(t_{\circ}\right)$ can be estimated even when the form of the curve $g$ is unknown. If we can assume that $g$ is smooth, then a method for estimating the curve $g$ is to apply linear regression modeling locally. Hence the curve $g\left(t_{i}\right)$ can be approximated as linear in a sufficiently small neighborhood around any given time point $t_{\mathrm{o}}$. One can simply apply the least-squares technique to a fraction of the data around $t_{\circ}$, or, alternatively, one can incorporate a weight scheme into the least squares problem that decreases the influence of data points in proportion to their distance from $t_{\circ}$. Such estimators are described, e.g. in Cleveland (1979), in Simonoff (1996) or in Fan and Gijbels (1996).

Separating the three components in Eq. (1) is an ill-posed problem without additional information. We argue here for assuming that the baseline signal $g$ must vary very slowly relative to any contributions of regional signal and that this regional signal $m$ is zero at many time points $t_{i}$. Then the basic idea of the "robust extraction of baseline signal (REBS)" technique is to regard measurement points $Y\left(t_{i}\right)$ as outliers if $m\left(t_{i}\right) \gg \sigma$ which is satisfied at time points $t_{i}$ that show clear contributions of regionally polluted air masses. Since the regional signal must be non-negative, that is $m\left(t_{i}\right) \geq 0$, all of the outliers point in the same direction and thus we have an asymmetric contamination of the baseline signal. In such a case, Ruckstuhl et al. (2001) suggest estimating the baseline signal by applying their robust baseline estimation technique. That is, solve

$$
\begin{aligned}
\widehat{\boldsymbol{\theta}}\left(t_{\circ}\right)= & \arg \min _{\boldsymbol{\theta}} \sum_{i=1}^{n} w_{\mathrm{r}}\left(t_{i}\right) K\left(\frac{t_{i}-t_{\circ}}{h}\right) \\
& \times\left[y_{i}-\left\{\theta_{0}+\theta_{1}\left(t_{i}-t_{\circ}\right)\right\}\right]^{2} .
\end{aligned}
$$

Note that the resulting estimated parameters $\widehat{\boldsymbol{\theta}}=\left(\widehat{\theta_{0}}, \widehat{\theta}_{1}\right)^{T}$ depend on $t_{\circ}$. Thus, $\widehat{\theta}_{0}\left(t_{\circ}\right)$ is an estimate of $g(t)$ at $t_{\circ}$ and is better named $\widehat{g}\left(t_{\circ}\right)$. To obtain an estimate of the whole baseline signal $g$, we solve Eq. (2) for a set of time grid points $t_{\circ}=\widetilde{t}_{k}, k=1, \ldots, K$ and interpolate them linearly (the original time points $t_{i}$ may also be selected as time grid points $\left.\widetilde{t}_{k}\right)$.

As kernel weight function $K\left[\left(t_{i}-t_{\circ}\right) / h\right]$, the tricube kernel

$K\left(\frac{t_{i}-t_{\circ}}{h}\right)=\left[\max \left\{1-\left|\frac{t_{i}-t_{\circ}}{h}\right|^{3}, 0\right\}\right]^{3}$

is used which descends smoothly to zero and is zero outside the neighborhood $t_{\circ} \pm h$. To down-weight the outlying regional signal $m\left(t_{i}\right)$, an asymmetric robustness weight $w_{\mathrm{r}}\left(t_{i}\right)$ is introduced:

$w_{\mathrm{r}}\left(x_{i}\right)= \begin{cases}1 & \text { if } r_{i}<0 \\ {\left[\max \left\{1-\left(r_{i} / b\right)^{2}, 0\right\}\right]^{2}} & \text { otherwise, }\end{cases}$

where $r_{i}=\left[y_{i}-\widehat{g}\left(x_{i}\right)\right] / \sigma$. The standard choice for the tuning constant $b$ is 3.5 ; however, any value for $b$ within 3 and 4 seems appropriate (see Maronna et al. (2006) for a discussion of the choice for $\mathrm{b}$ in a general context). On one hand, outliers might receive too much weight when $b$ is larger than 4 . On the other hand, the smaller the tuning constant is, the higher the systematic error in time series with no or a very small number of polluted measurements. It should, however, be noted that the use of asymmetric robustness weights also helps to ensure that the fit converges to an acceptable solution.

A critical issue for the REBS technique is how wide the local neighborhood should be (i.e. what value of socalled bandwidth $h$ ). A number of suggestions have been advanced for automatically determining an appropriate bandwidth from the data (Simonoff, 1996; Fan and Gijbels, 1996). However, these approaches would lead to reasonable bandwidths $h$ for estimating the "total" signal $g\left(t_{i}\right)+m\left(t_{i}\right)$, which is not our goal. A more problem-specific consideration is the following: if, in a local neighborhood of $t_{\circ}$ consisting of $d$ data points, at least $d / 2$ of them are seriously affected by the regional signal $m$, then the robust local regression estimator is more likely to estimate $\left(g\left(t_{\circ}\right)+m\left(t_{\circ}\right)\right)$ than $g\left(t_{\circ}\right)$. To avoid such a failure, we can require that $d$ must be large enough such that, at very least, less than half of the points in the local neighborhood for any $t_{\circ}$ have significant regional signal $m$. The smallest possible value of $d$ we refer to as $d_{\circ}$; in extraction of baseline signals, $d_{\circ}$ would be roughly twice the length of the longest regional signal (measured in numbers of measurements). The difficulty we face with this approach is to clearly separate the baseline signal from the regional signal. As earlier discussed, this is generally an ill-defined problem and can be solved only with additional assumptions on the baseline signal. Considering this difficulty, we prefer to separate baseline signals from regional signals by defining the baseline signal as the estimated smooth curve obtained from the REBS technique using a sufficiently wide bandwidth (e.g. 90 days). Such an approach seems reasonable 


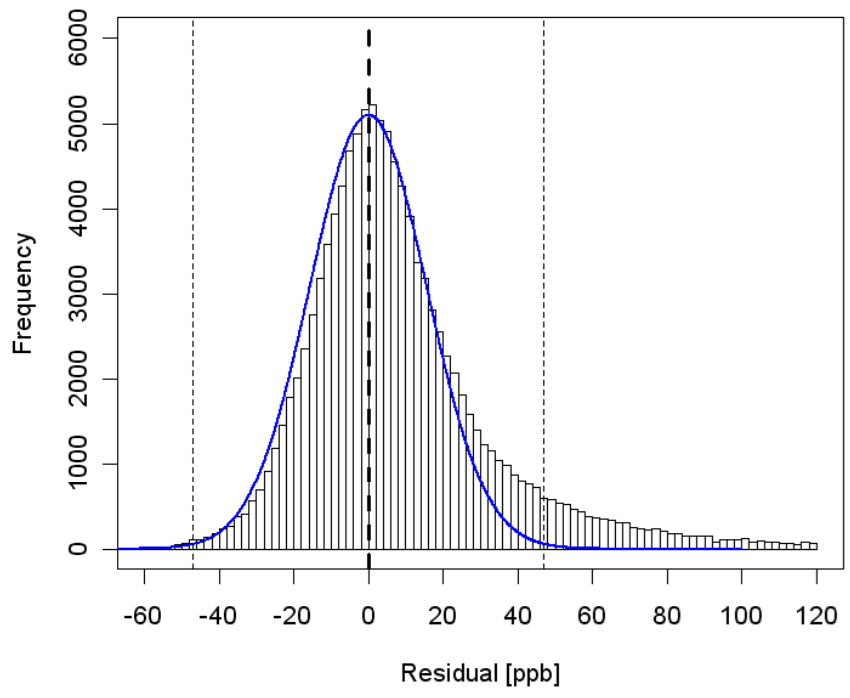

Fig. 1. Histogram of the residuals derived from application of the REBS technique to hourly CO measurements at Jungfraujoch. The estimated scale parameter $\sigma$ is $15.6 \mathrm{ppb}$. The thick vertical dashed line indicates the estimated mode of the residual distribution; the two thin vertical dashed lines denote the $\pm 3 \sigma$ range. The blue line is a Gaussian distribution fitted to the left side (residuals below the mode) of the residual distribution. The residual distribution can be used for judgement of the applicability of the REBS technique. The REBS should only be applied when the residuals below the mode follow approximately a Gaussian distribution (see Sect. 5).

when assuming a regional signal of length shorter than one month and assuming a baseline signal which varies slowly relative to the regional signal. On the other hand, the bandwidth is short enough to account for possible seasonal effects. The selection of the bandwidth should, however, be done carefully. Selection of a too wide bandwidth can easily be identified from a seasonal variation that prevails in the time series of the residuals.

Finally, in order to implement the REBS technique, the scale parameter $\sigma$ (i.e. the measurement noise) needs to be specified. In certain cases, $\sigma$ can be estimated a priori, e.g. based on the precision of the measurement device. Note that this, however, would neglect the fraction of $\sigma$ that is due to variability in the baseline signal. When no a priori information is available, $\sigma$ must be estimated from the measurements themselves. Since there may be many time points, where the regional signal $m$ is close to 0 , the right side of the residual distribution (the positive residuals) may be longtailed due to measurements of locally or regionally polluted air masses. Consequently, the scale parameter $\sigma$ is calculated from the standard deviation of the negative residuals only:

$\widehat{\sigma}_{\text {asd }}=\sqrt{\frac{1}{\#\left\{i: r_{i} \leq 0\right\}} \sum_{i: r_{i} \leq 0} r_{i}^{2}}$.

In an ordinary (local) least-squares fit or in many REBS applications, the mode of the residuals is at 0 . In some ap- plications the mode is below 0 and estimation of the scale parameter using Eq. (5) results in a too large estimate for $\sigma$. In these cases all residuals below the mode, instead of all negative residuals, are used for estimation of $\sigma$ :

$\widehat{\sigma}_{\text {masd }}=\sqrt{\frac{1}{\#\left\{i: r_{i} \leq \widehat{\mu}\right\}} \sum_{i: r_{i} \leq \widehat{\mu}}\left(r_{i}-\widehat{\mu}\right)^{2}}$,

where $\widehat{\mu}$ is the estimated mode of residual distribution. Unfortunately, the estimation of the mode of an empirical distribution is challenging. We use either a nonparametric density estimator as they are described e.g. in Simonoff (1996) and in Fan and Gijbels (1996) or we simply use a histogram with many classes.

In both approaches, the precision of the measuring instrument (e.g. the standard deviation of working standard measurements) can be considered as a lower bound for the estimate of the scale parameter.

To summarize, the REBS technique proceeds as follows:

1. For each observation $Y\left(t_{i}\right)$, compute $\widehat{g}\left(t_{i}\right)$ by using the local regression estimator of Eq. (2) with the kernel weights defined by Eq. (3) and robustness weights $w_{\mathrm{r}}\left(t_{i}\right)=1$.

2. Use Eq. (5) or Eq. (6) to estimate the scale parameter $\sigma$ and calculate the robustness weights $w_{\mathrm{r}}\left(x_{i}\right)$ by applying Eq. (4).

3. For each observation $Y\left(t_{i}\right)$, compute a new fitted value $\widehat{g}\left(t_{i}\right)$ by using the robust local regression estimator of Eq. (2) with kernel weights defined by Eq. (3).

4. Repeat steps 2 and 3 until convergence, which generally requires about 5-10 iterations. The final fitted values yield the estimated curve $\widehat{g}\left(t_{i}\right)$.

5. All observations $Y\left(t_{i}\right)$ with $Y\left(t_{i}\right) \leq \widehat{g}\left(t_{i}\right)+3 \sigma$ are classified as "background" measurements; all other observations are classified as "polluted".

\subsection{The uncertainty in the resulting curve}

Confidence bands are the common notions to formalize the uncertainty of fitted curves. Classically, they are based on analytical deviations from the asymptotic distribution of the fitted values. In our case, such an approach is very tedious since we use asymmetric robustness weights. Thus we propose to use the bootstrap approach (Efron and Tibshirani, 1993) which is a general-purpose technique for obtaining information such as confidence bands by simulation. The basic idea is to repeatedly simulate from the residuals new sample sets of residuals and hence compute sets of pseudoresponses. With each set of pseudo-responses, a new baseline signal is extracted. This is repeated $B$ times. To take into account the temporal spread of the regional signal, we resample from blocks of consecutive residuals. In our setting, the blocks do overlap. 


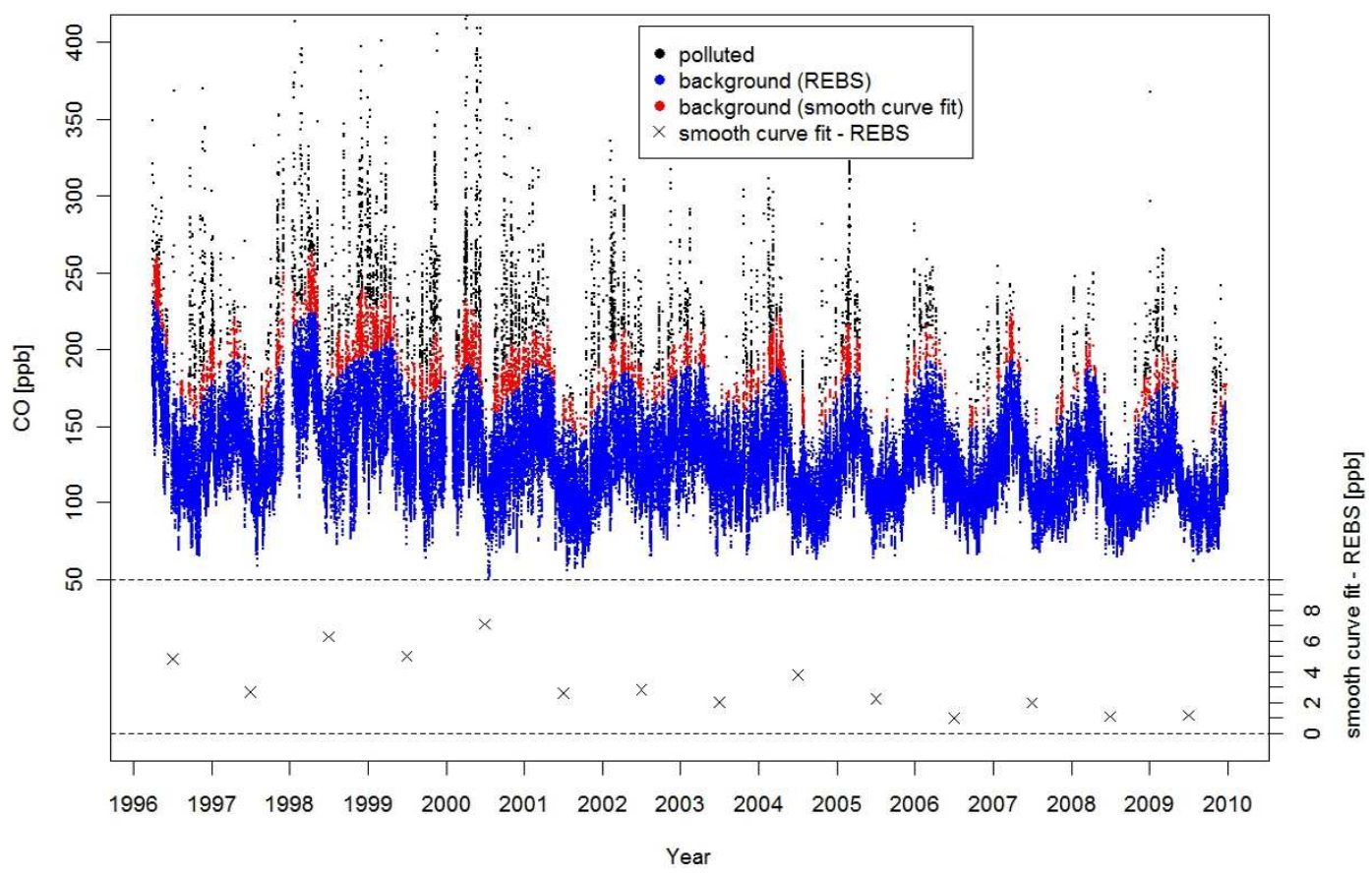

Fig. 2. Measured CO during impact of regionally polluted air masses (black points) and background CO concentrations at Jungfraujoch for the 1996-2009 period as identified by the REBS technique and the smooth curve fit. The black crosses indicate the difference of annual background concentrations obtained by the two data filtering methods.

When robust estimates are bootstrapped, two problems arise: numerical instability and computational cost. The first problem is due to very poor estimates resulting from the bootstrap pseudo-responses, which may contain a higher proportion of regional signal than the original data. The latter problem is due to the complex estimation procedure, which must be used in order to calculate robust estimates.

To overcome these problems, Salibian-Barrera and Zamar (2002) propose the so-called robust bootstrap which is fast and can resist large proportion of outliers in the bootstrap pseudo-responses. Their idea is to bootstrap the pair residuals $r_{i}$ and robustness weights $w_{\mathrm{r}}\left(x_{i}\right)$ simultaneously and use the corresponding robustness weights for the pseudo-responses in a one-step iteration of the REBS technique. This idea does, however, not take into account the uncertainty caused by estimating the robustness weights. Hence confidence intervals based on this modified bootstrap idea must be corrected as suggested in Salibian-Barrera and Zamar (2002). As the REBS technique implies to calculate the corrections at each point $t_{0}$, the computation of these corrections is (too) timeconsuming. Thus we simplify the correction by taking the experience into account that the uncorrected confidence intervals are about 10 to $20 \%$ too small. So we end up enlarging the uncorrected confidence intervals by the factor 1.2. By this modification, we should still get a fair idea of the uncertainty in the curve estimated by the REBS technique. Note that the resulting bootstrap confidence intervals are generally asymmetric due to the asymmetric robustness weights as defined in Eq. (4).

\section{Experimental}

\subsection{Measurement sites}

The proposed approach for determination of baseline concentrations is applied to measurements from two sites: the high-alpine site Jungfraujoch and the coastal site Mace Head. Jungfraujoch (JFJ, $3580 \mathrm{~m}$ a.s.l.) is located on the main crest of the Bernese Alps, Switzerland, and belongs to the Swiss National Air Pollution Monitoring Network (NABEL). The Mace Head station (MHD) is situated on the west coast of Ireland; Mace Head is, like Jungfraujoch, part of AGAGE and the Global Atmosphere Watch (GAW) programme of WMO.

\subsection{CO measurements at Jungfraujoch}

Carbon monoxide is a trace gas that mainly results from combustion emissions (fossil fuel combustion and biomass burning) and oxidation of methane and other hydrocarbons (Jacob, 1999) in the atmosphere. CO is removed from the atmosphere predominantly by reaction with the $\mathrm{OH}$ radical. $\mathrm{CO}$ at Jungfraujoch has been continuously monitored since 1996 using commercially available NDIR monitors (APMA360 and APMA-370, Horiba). Modification of the instrument 
included drying of the air by a Nafion dryer in split flow mode (Perma Pure PD-50T-24"). The CO instrument is calibrated approximately in monthly intervals using a commercial CO calibration gas referenced against NIST (National Institute of Standards and Technology), SRM (Standard Reference Material), and NMI (Netherlands Measurement Institute), PRM (Primary Reference Material) all being consistent with the WMO-2000 scale. Automatic instrument zero checks were performed every $49 \mathrm{~h}$ using zero air. The detection limit for individual $1 \mathrm{~min}$ values is $20 \mathrm{ppb}$; the overall measurement uncertainty was estimated to be $\pm 5 \%(1 \sigma)$ (Zellweger et al., 2000). In Zellweger et al. (2009) different $\mathrm{CO}$ measurement techniques were compared during a field campaign at JFJ. It was confirmed that the NDIR method is suitable for $\mathrm{CO}$ measurements at this site.

\subsection{Measurement of HFC-152a at Jungfraujoch and Mace Head}

HFC-152a (1,1-difluoroethane, $\mathrm{CH}_{3} \mathrm{CHF}_{2}$ ) is a replacement compound for chlorofluorocarbons (CFCs) and hydrochlorofluorocarbons (HCFCs) and is mainly used in foam blowing applications. The observation of atmospheric concentrations of HFC-152a is of importance, because HFC-152a shows (like other HFCs) strong absorption of infrared radiation and is a greenhouse gas included in the Kyoto Protocol. HFC-152a has been measured at Jungfraujoch and Mace Head within the AGAGE program since 2000 (JFJ) and 1994 (MHD) using preconcentration systems in combination with gas-chromatograph mass spectrometers (GC-MS). The temporal resolution of the measurements was $4 \mathrm{~h}$ until December 2004 at Mace Head and until April 2008 at Jungfraujoch. Since then, air samples are analysed every $2 \mathrm{~h}$. The details of the applied experimental methods are given in Simmonds et al. (1995) and Miller et al. (2008).

\subsection{Baseline determination by the smooth curve fit}

The proposed REBS technique is compared with a method similar to that developed by Thoning et al. (1989) and further refined and applied by Novelli et al. (1998) and Novelli et al. (2003). This data filtering and baseline determination technique is denoted here as the smooth curve fit (see Sect. 1). For the smooth curve fit, the measured data are fitted by the parametric function

$$
\begin{aligned}
& f\left(t_{i}\right)=a_{1}+a_{2} t_{i}+a_{3} t_{i}^{2}+ \\
& \sum_{j=1}^{4}\left[a_{(2 j+2)} \sin \left(2 \pi j t_{i}\right)+a_{(2 j+3)} \cos \left(2 \pi j t_{i}\right)\right]
\end{aligned}
$$

where $t_{i}$ is the time of observation $i$. The polynomial in Eq. (7) represents the trend; the sum of harmonics is an approximation of the average seasonal cycle. The residuals of the fit of Eq. (7) were converted into the frequency domain by a Fourier transform algorithm and filtered using first a low- pass filter (50\% transmission at 80 days) and second a highpass filter (50\% transmission at 667 days). Since Fourier transform requires data with regular sampling intervals, the measurements were matched to fixed intervals that approximately correspond to the data frequency. The filtered residuals were then transformed back into the time domain and added to the fitted function providing the smooth curve fit. Measurements with deviation outside the $\pm 3 \sigma$ range around the smooth curve fit were identified as outliers (or nonbackground measurements) and removed from the data. The above-described procedure was run iteratively until no more outliers were found. Note that in, contrast to the REBS technique, low outliers (concentration below the fitted baseline $-3 \sigma)$ are also removed and classified as non-background measurements.

\subsection{Background measurement identification by the AGAGE method}

The measurements at AGAGE sites are routinely flagged as polluted or background observations using a statistical filtering procedure briefly outlined in Sect. 1 and described in detail by O'Doherty et al. (2001). The results of the AGAGE method applied to HFC-152a at Mace Head and Jungfraujoch are compared in Sect. 4 with background identification using the REBS and the smooth curve fit. Note that, unlike REBS and the smooth curve fit, the AGAGE method does not provide baseline curves. The AGAGE method is a procedure for identification for background and polluted observations. It is not easily available and applicable for users. Therefore, the background and pollution flags for HFC-152a at Jungfraujoch and Mace Head were taken from the AGAGE database.

\section{Results and discussion}

\subsection{Identification of $\mathrm{CO}$ background measurements at Jungfraujoch}

Background concentrations might be understood as "the concentration of a given species in a pristine air mass in which anthropogenic impurities of relatively short lifetime are not present" (Calvert, 1990). Consequently, background measurements should be normally distributed with a mode representing the mean background concentration. Therefore, the left side of the distribution of the residuals from a baseline fitting technique (the residuals below the mode of the distribution) should approximately follow a Gaussian distribution as well. As indicated by Balzani Lööv et al. (2008), the above definition of background conditions is only valid for longlived compounds. For compounds with short or medium lifetime, a generally applicable definition of background does not exist.

Figure 1 shows the histogram of the residuals for the REBS technique applied to hourly CO measurements at Jungfraujoch for the period from 1996 to 2009. CO has an 
Table 1. Contingency table of the classification of the hourly CO values measured at Jungfraujoch from 1996 to 2009 ( $n=111656)$ derived from the REBS technique and the smooth curve fit.

\begin{tabular}{lrrr}
\hline & \multicolumn{2}{c}{ smooth curve fit } \\
\cline { 3 - 4 } & & background & polluted \\
\hline \multirow{3}{*}{ REBS } & background & 102446 & 231 \\
& & $(91.8 \%)$ & $(0.2 \%)$ \\
& polluted & 5041 & 3938 \\
& & $(4.5 \%)$ & $(3.5 \%)$ \\
\hline
\end{tabular}

average lifetime of about two months that strongly varies from tens of days to up to one year depending on season and location and is therefore not well-mixed in the troposphere (Jacob, 1999; Holloway et al., 2000). Nevertheless, the left side of the residual distribution follows approximately a Gaussian distribution; the estimate for the scale parameter $\sigma$ is $15.6 \mathrm{ppb}$. As mentioned in Sect. 1, the scale parameter $\sigma$ is an upper limit for the precision of the instrument. However, the obtained value for $\sigma$ is considerably larger than the random uncertainty of the NDIR instrument (4.2 ppb), which was determined from the standard deviation of repeated zero air measurements (Zellweger et al., 2009). The larger scale parameter $\sigma$ might be a consequence of the deviations from the concept of background conditions mentioned above: the relatively short lifetime of $\mathrm{CO}$ mainly due to oxidation by $\mathrm{OH}$ leads to a latitudinal gradient for $\mathrm{CO}$, and therefore to a dependence of the background concentration at Jungfraujoch on the air mass origin.

Classification of background measurements $Y\left(t_{i}\right)$ by $Y\left(t_{i}\right) \leq \widehat{g}\left(t_{i}\right)+3 \sigma$ (Sect. 2) leads to an overestimation of the number of background measurements and to a small bias in estimated baseline curves. This can be seen from Fig. 1, where the frequencies of the residuals that are larger than the mode of the residual distribution are higher than expected from the fitted Gaussian distribution (bars in Fig. 1 exceeding the blue line). A possible way to adjust for this small bias could be to randomly select an appropriate number of residuals in the range between the mode of the residual distribution and the mode $+3 \sigma$ and to consider them as "polluted" measurements, so that the shape of the histogram of the remaining residuals of background measurements would follow the Gaussian distribution (blue line in Fig. 1). Such a correction has not been done within this work.

The time series of polluted and background CO measurements at Jungfraujoch as classified by the REBS technique and the smooth curve fit are shown in Fig. 2. In Table 1, the number of hourly $\mathrm{CO}$ measurements at Jungfraujoch from 1996 to 2009 that are classified as "background" and as "polluted" by the REBS and the smooth curve fit is listed. The classification by the two methods is very similar, although the REBS classifies about $4.5 \%$ of the observations as "polluted" that are considered as representative for background

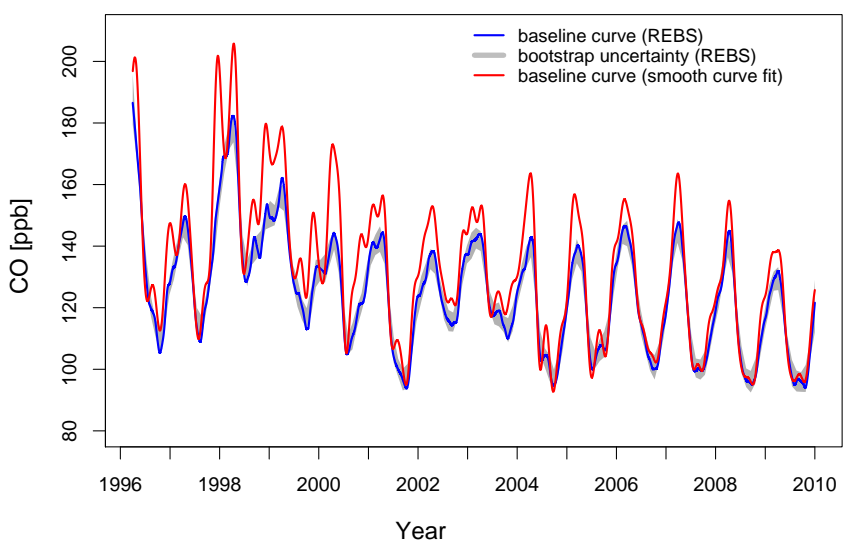

Fig. 3. Baseline curves for CO at Jungfraujoch (1996 to 2009) obtained with the REBS technique (including the bootstrapped $95 \%$ confidence band) and the smooth curve fit. The average width of the confidence band (bootstrap uncertainty) is $(-3.5 \mathrm{ppb},+3.8 \mathrm{ppb})$.

conditions by the smooth curve fit. This difference in classification is probably due to the different iterative procedure for identification of background observations: As described in Sect. 2, the accepted deviation of background measurements from the baseline fit is calculated by the REBS technique only from the residuals that are smaller than the mode of the residual distribution. In the smooth curve fit, the standard deviation $\sigma$ is calculated from all residuals, and measurements within the $\pm 3 \sigma$ range around the fitted baseline curve are considered as representative for background conditions (Sect. 3.4). In contrast to the REBS, some of the lowest measured concentrations are identified as outliers by the smooth curve fit. Consequently, a small fraction of measured $\mathrm{CO}$ concentrations $(0.2 \%)$ that are classified by the REBS as "background" are classified as non-background by the smooth curve fit (in Table 1 denoted as "polluted").

The differences in the classification of background measurements lead to small differences in annual average background $\mathrm{CO}$ concentrations but to clear differences during the cold season. Annual background CO concentrations for the 1996 to 2009 period obtained with the REBS technique are on average $3.2 \mathrm{ppb}$ lower (range 1.0 to $7.1 \mathrm{ppb}$ ) than those obtained from the smooth curve fit.

It should be noted that the enhancements in annual background CO at Jungfraujoch in 1998 as well as in 2002 and 2003 (Fig. 2) are probably due to the impact of emissions from widespread boreal forest fires reported by Novelli et al. (2003) and Yurganov et al. (2005).

\subsection{Estimation of the CO baseline at Jungfraujoch}

Figure 3 shows the estimated baseline curve for the REBS technique including the $95 \%$ bootstrap confidence band. As indicated in Sect. 2.2, the bootstrap confidence interval is asymmetric around the estimated baseline; the average width of the confidence band ranges from $-3.5 \mathrm{ppb}$ to $3.8 \mathrm{ppb}$. As 

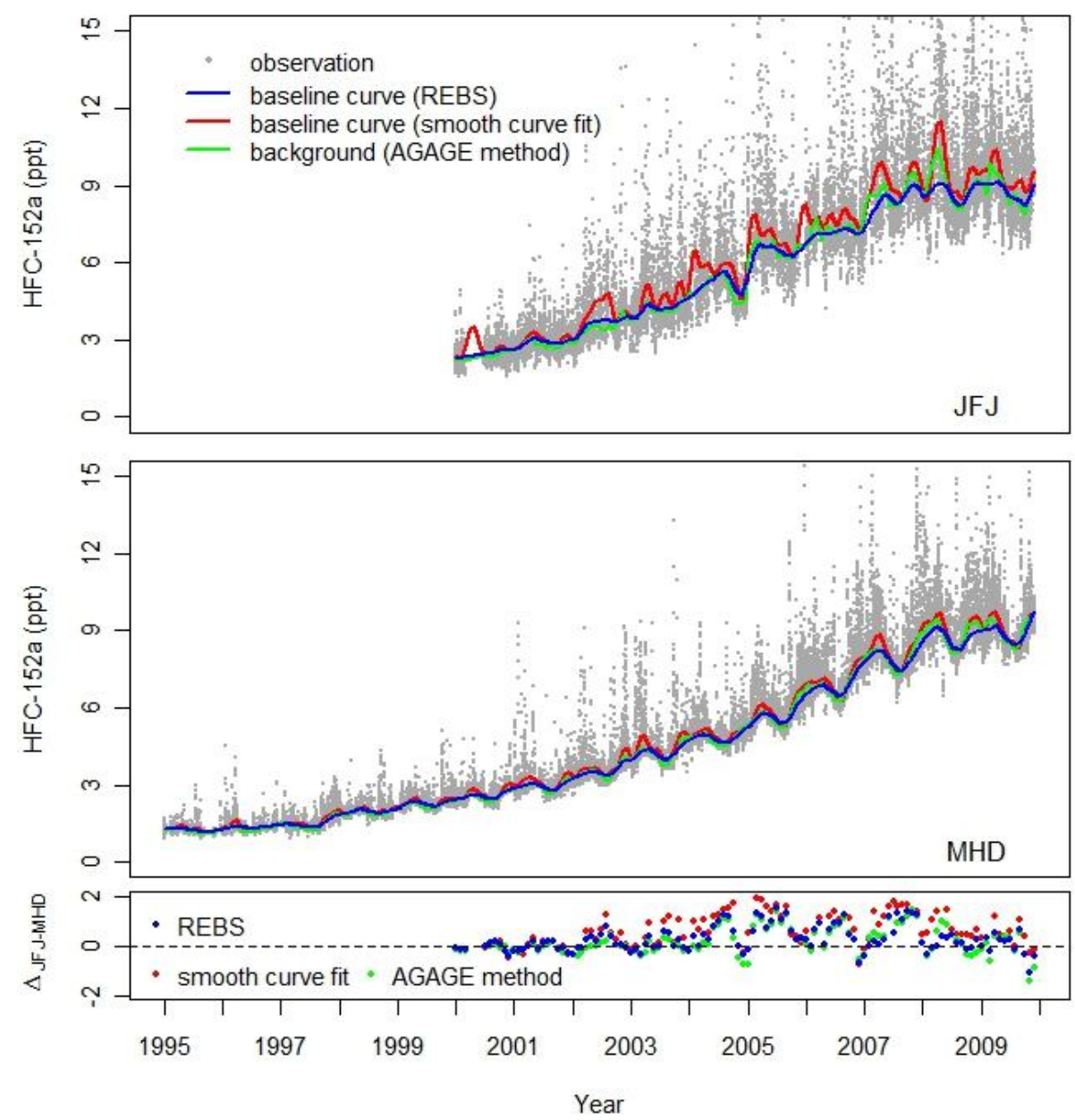

Fig. 4. Measurements and baseline curves for HFC-152a at Jungfraujoch (2000 to 2009, top panel) and Mace Head (1995 to 2009, middle panel) estimated with the REBS technique and the smooth curve fit. The time series of monthly mean background concentration of HFC-152a calculated with the AGAGE method (see text) are also included. The lower panel gives the difference of monthly background concentrations at Jungfraujoch and Mace Head (in ppt) as determined with the REBS, the smooth curve fit, and the AGAGE method.

the bootstrap confidence band indicates, some of the wiggles in the estimated baseline signal may not be statistically significant. This may also mean that the true baseline signal is somewhat smoother than estimated by the REBS. Hence one might be tempted to increase the bandwidth $h$. However, a large bandwidth $h$ has the disadvantage of over-smoothing true temporal variability.

For comparison, the baseline curve obtained from the smooth curve fit is also included in Fig. 3. The baseline curve derived from the REBS technique is generally somewhat lower than the baseline curve from the smooth curve fit. There is good agreement between the two approaches during the warmer season when background $\mathrm{CO}$ concentrations are lowest due to oxidation by $\mathrm{OH}$, and considerable disagreement during the cold period when background $\mathrm{CO}$ concentrations are highest. These differences would be of importance when emission estimates are performed using techniques as described e.g. by Reimann et al. (2005), Simmonds et al.
(2001) and Greally et al. (2007) that are based on concentration above background estimates.

The linear trend of the $\mathrm{CO}$ background concentration was determined from regression of the annual means of the identified $\mathrm{CO}$ background concentrations against time. The average annual change for the 1996 to 2009 period as determined from the REBS filtered data is $-2.2 \pm 1.1 \mathrm{ppbyr}^{-1}$; data filtering using the smooth curve fit results in $-2.5 \pm 1.1 \mathrm{ppb} \mathrm{yr}^{-1}$, a slightly larger, although not statistically significant, decrease of background $\mathrm{CO}$ (see also the study by Zellweger et al. (2009) for a discussion of the trend of CO at Jungfraujoch for the 1996 to 2007 period). Note that the linear negative trend of unfiltered hourly $\mathrm{CO}$ measurements for this time period is considerably larger $\left(-2.9 \pm 1.3 \mathrm{ppb} \mathrm{yr}^{-1}\right)$ due to more severe and more frequent pollution events during the first years of the considered time period (see Fig. 2). It has been shown by Zellweger et al. (2009) that the negative trend of CO at Jungfraujoch is 
Table 2. Contingency table of the classification of HFC-152a measurements at Jungfraujoch from 2000 to $2009(n=15815)$ with the REBS technique, the smooth curve fit, and the AGAGE method ( $b=$ background; $p=$ polluted).

\begin{tabular}{cccrr}
\hline REBS & $\begin{array}{c}\text { smooth } \\
\text { curve fit }\end{array}$ & $\begin{array}{c}\text { AGAGE } \\
\text { method }\end{array}$ & Frequency & $(\%)$ \\
\hline $\mathrm{b}$ & $\mathrm{b}$ & $\mathrm{b}$ & 12241 & 77.4 \\
$\mathrm{p}$ & $\mathrm{b}$ & $\mathrm{b}$ & 84 & 0.5 \\
$\mathrm{~b}$ & $\mathrm{p}$ & $\mathrm{b}$ & 12 & 0.1 \\
$\mathrm{p}$ & $\mathrm{p}$ & $\mathrm{b}$ & 0 & 0.0 \\
$\mathrm{~b}$ & $\mathrm{~b}$ & $\mathrm{p}$ & 1898 & 12.0 \\
$\mathrm{p}$ & $\mathrm{b}$ & $\mathrm{p}$ & 946 & 6.0 \\
$\mathrm{~b}$ & $\mathrm{p}$ & $\mathrm{p}$ & 0 & 0 \\
$\mathrm{p}$ & $\mathrm{p}$ & $\mathrm{p}$ & 634 & 4.0 \\
\hline
\end{tabular}

mainly the result of the reduction of European emissions since the early 1990s.

\subsection{Baseline of HFC-152a at Jungfraujoch and Mace Head}

As a second application of the REBS technique, baselines of HFC-152a measured at Jungfraujoch and Mace Head are estimated. The bandwidth of the REBS was again chosen to be 90 days. Figure 4 shows the measurements of HFC152a at Jungfraujoch and Mace Head, the baselines determined with the REBS and the smooth curve fit, as well as the monthly mean concentration of the background observations as identified by the AGAGE method. Similar to CO at Jungfraujoch, the baseline of HFC-152a determined with the REBS approach is at Jungfraujoch and Mace Head somewhat lower than the baseline curve resulting from the smooth curve fit. The differences between the two methods are more pronounced at Jungfraujoch probably due to more frequent and larger pollution events than at Mace Head. On the other hand, there is a good agreement between the baseline determined with the REBS and the monthly mean background concentrations derived with the AGAGE method, although there are some obvious differences for the measurements at Jungfraujoch after about 2006.

The atmospheric lifetime of HFC-152a is about $1.4 \mathrm{yr}$; degradation of this compound is dominated by reaction with $\mathrm{OH}$ (Greally et al., 2007, and references therein). Consequently, it can be expected that HFC-152a is well mixed in the northern hemispheric troposphere and the baselines at Mace Head and Jungfraujoch should be comparable. The lower panel of Fig. 4 shows the differences of the monthly mean concentrations of the background observations at Jungfraujoch and Mace Head as derived with the three applied methods. From 2000 to about 2002, when background concentrations of HFC-152a were still quite low, Jungfraujoch and Mace Head had very similar background concentrations. With increasing pollution events after 2002,
Table 3. Contingency table of the classification of HFC-152a measurements at Mace Head from 1995 to $2009(n=28694)$ with the REBS technique, the smooth curve fit, and the AGAGE method ( $b=$ background; $\mathrm{p}=$ polluted).

\begin{tabular}{cccrr}
\hline REBS & $\begin{array}{c}\text { smooth } \\
\text { curve fit }\end{array}$ & $\begin{array}{c}\text { AGAGE } \\
\text { method }\end{array}$ & Frequency & $(\%)$ \\
\hline b & $\mathrm{b}$ & $\mathrm{b}$ & 21177 & 73.8 \\
$\mathrm{p}$ & $\mathrm{b}$ & $\mathrm{b}$ & 426 & 1.5 \\
$\mathrm{~b}$ & $\mathrm{p}$ & $\mathrm{b}$ & 229 & 0.8 \\
$\mathrm{p}$ & $\mathrm{p}$ & $\mathrm{b}$ & 15 & 0.1 \\
$\mathrm{~b}$ & $\mathrm{~b}$ & $\mathrm{p}$ & 3236 & 11.3 \\
$\mathrm{p}$ & $\mathrm{b}$ & $\mathrm{p}$ & 1331 & 4.6 \\
$\mathrm{~b}$ & $\mathrm{p}$ & $\mathrm{p}$ & 23 & 0.1 \\
$\mathrm{p}$ & $\mathrm{p}$ & $\mathrm{p}$ & 2257 & 7.9 \\
\hline
\end{tabular}

the HFC-152a background at Jungfraujoch was higher than at Mace Head, most likely because of the closer proximity of the Jungfraujoch to major source regions (Greally et al., 2007; Reimann et al., 2008). Since about 2008, the HFC152a background concentration at Jungfraujoch has been declining (probably due to stabilizing emissions) and again very close to the background concentration at Mace Head. All three applied methods for identification of background observations (REBS, smooth curve fit and AGAGE method) result in very similar differences of monthly background concentrations at Jungfraujoch and Mace Head.

The Tables 2 and 3 provide the number and percentage of HFC-152a measurements at Jungfraujoch and Mace Head that are classified as "background" and as "polluted" by the REBS technique, the smooth curve fit, and the AGAGE method. The classification agrees at both sites for $81-82 \%$ of the observations. However, about $5 \%$ of the measurements are classified as "polluted" by the REBS and the AGAGE method but identified as "background" by the smooth curve fit. The remaining $12.0 \%$ and 11.3 method, but classified as being representative for background conditions by the two other approaches. Hence, identification of background observations shows systematic differences between the applied methods: the AGAGE method leads to the lowest number of background concentrations, followed by the REBS technique. The smooth curve fit, on the other hand, seems to ignore some pollution events, very likely due to the different procedures for identification of background observations as described in Sect. 4.

\section{Applicability of the REBS}

As discussed in Sect. 4.1, trace gases (e.g. CO) can show latitudinal gradients due to the dependence of emissions and sinks on latitude. If strong latitudinal transport events reach a sampling location, observations might therefore not be representative of the latitudinal background concentration at the 
considered sampling site. In addition, terrestrial sinks can also lead to "depletion events". Statistical filtering methods including the REBS and most meteorological filters cannot correctly cope with the effect of latitudinal gradients and terrestrial sinks. For the REBS, it is suggested that the residual distribution (as shown for $\mathrm{CO}$ at Jungfraujoch in Fig. 1) is used for judgment of the applicability of the REBS for the time series of interest. The left-hand site of the residual distribution should approximately follow a Gaussian distribution. Obvious deviations from this requirement indicate a significant impact of latitudinal transport, terrestrial sinks or other processes leading to observations that are well below the background concentration at the sampling site. Observations well below the background concentration receive too high weights (see Eq. 4) and consequently lead to a baseline estimation that is biased downwards.

The REBS approach was recently extended by including the latitude of air mass origin taken from back-trajectories as a second dimension in the local regression. This extended version has already been applied for estimation of baseline concentrations of $\mathrm{H}_{2}$ at Jungfraujoch (Bond et al., 2011) and denoted as 2D-REBS. The details of this approach will be subject of a forthcoming publication.

A final issue to consider is missing data. The impact of data gaps on the resulting baseline curve was investigated using the hourly $\mathrm{CO}$ measurements from Jungfraujoch. Thus, continuous data gaps of different lengths $(1,10,30,45,60$, 90 , and 180 days) have artificially been inserted. For each data gap length, 100 baseline estimations at randomly chosen gap positions have been performed. The maximum deviation of the estimated baseline curves with data gap from the original measurements without artificial data gap has been determined up to 90 days (i.e. the selected bandwidth) before the beginning and 90 days after the end of the inserted data gap. The maximum deviation of estimated baselines with data gaps up to 30 days is within the uncertainty of the baseline curve (see Fig. 3). For data gaps wider than the selected bandwidth, the maximum deviation goes up to about $9 \mathrm{ppb}$. We conclude that the REBS technique can handle data gaps with satisfactory accuracy and do not recommended to fill missing values.

\section{Conclusions}

A statistical method based on robust local regression is introduced. The presented REBS technique was applied for identification of background $\mathrm{CO}$ measurements at the high-alpine background site at Jungfraujoch, and for determination of background observations of HFC-152a at Jungfraujoch and Mace Head. The results were compared to those from more common approaches denoted here as the smooth curve fit and the AGAGE method.
The different methods applied resulted in similar selection of background measurements, although systematic differences have been observed. For HFC-152a at Jungfraujoch and Mace Head, the AGAGE method identifies a lower number of observations as being representative for background conditions than from the REBS technique and the smooth curve fit. However, the differences in average background concentrations between AGAGE method and REBS technique are very small; the differences in average background concentrations between REBS and the smooth curve fit are larger. Although it seems that, in the applications performed within this study, the smooth curve fit missed some polluted observations, it is not possible to state which of the three methods performed best. For some applications, the observed differences are negligible. For others, the selection of the method for identification of background concentrations might have a non-negligible effect on the result. Nevertheless, an important advantage of the REBS technique over the AGAGE method and the smooth curve fit is that the software code is freely available, and that it therefore is more easily applicable for interested users.

Acknowledgements. The authors gratefully acknowledge the support from the International Foundation High-Altitude Research Stations Jungfraujoch and Gornergrat (HFSJG), and the custodians at the Jungfraujoch research station for their hospitality. The CO measurements at JFJ are part of the Swiss National Air Pollution Monitoring Network (NABEL) and supported by the Swiss Federal Office for the Environment (FOEN). Many thanks also to Arlyn Andrews (NOAA) for data filtering using the smooth curve fit and to Ray H. J. Wang (Georgia Tech) for the AGAGE background filtering.

Edited by: A. J. M. Piters

\section{References}

Balzani Lööv, J. M., Henne, S., Legreid, G., Staehelin, J., Reimann, S., Prevot, A. S. H., Steinbacher, M., and Vollmer, M. K.: Estimation of background concentrations of trace gases at the Swiss Alpine site Jungfraujoch (3580 m asl), J. Geophys. Res., 113, DD22305, doi:10.1029/2007JD009751, 2008.

Bond, S. W., Vollmer, M. K., Steinbacher, M., Henne, S., and Reimann, S.: Atmospheric molecular hydrogen $\left(\mathrm{H}_{2}\right)$ : observations at the high-altitude site Jungfraujoch, Switzerland, Tellus B, 63, 64-76, doi:10.1111/j.1600-0889.2010.00509.x, 2011.

Calvert, J. G.: Glossary of Atmospheric Chemistry Terms (Recommondations 1990), Pure Appl. Chem., 62, 2167-2219, 1990.

Carpenter, L., Green, T., Mills, G., Bauguitte, S., Penkett, S., Zanis, P., Schuepbach, E., Schmidbauer, N., Monks, P., and Zellweger, C.: Oxidized nitrogen and ozone production efficiencies in the springtime free troposphere over the Alps, J. Geophys. Res., 105, 14547-14559, 2000.

Cleveland, W. S.: Robust Locally Weighted Regression and Smoothing Scatterplots, J. Am. Stat. Assoc., 74, 829-836, 1979. 
Cox, M. L., Sturrock, G. A., Fraser, P. J., Siems, S. T., and Krummel, P. B.: Identification of Regional Sources of Methyl Iodide from AGAGE Observations at Cape Grim, Tasmania, J. Atmos. Chem., 50, 59-77, 2005.

Derwent, R., Simmonds, P., O'Doherty, S., Ciais, P., and Ryall, D.: European source strengths and northern hemisphere baseline concentrations of radiatively active trace gases at Mace Head, Ireland, Atmos. Environ., 32, 3703-3715, 1998.

Efron, B. and Tibshirani, R. J.: An introduction to the bootstrap, Chapman \& Hall New York, 1993.

Fan, J. and Gijbels, I.: Local Polynomial Modelling and Its Applications, vol. 66 of Monographs on Statistics and Applied Probability, Chapman \& Hall New York, 1996.

Forrer, J., Rüttimann, R., Schneiter, D., Fischer, A., Buchmann, B., and Hofer, P.: Variability of trace gases at the high-Alpine site Jungfraujoch caused by meteorological transport processes, J. Geophys. Res., 105, 12241-12251, 2000.

Greally, B. R., Manning, A. J., Reimann, S., McCulloch, A., Huang, J., Dunse, B. L., Simmonds, P. G., Prinn, R. G., Fraser, P. J., Cunnold, D. M., O’Doherty, S., Porter, L. W., Stemmler, K., Vollmer, M. K., Lunder, C. R., Schmidbauer, N., Hermansen, O., Arduini, J., Salameh, P. K., Krummel, P. B., Wang, R. H. J., Folini, D., Weiss, R. F., Maione, M., Nickless, G., Stordal, F., and Derwent, R. G.: Observations of 1,1-difluoroethane (HFC-152a) at AGAGE and SOGE monitoring stations in 1994-2004 and derived global and regional emission estimates, J. Geophys. Res., 112, D06308, doi:10.1029/2006JD007527, 2007.

Henne, S., Furger, M., and Prevot, A.: Climatology of mountain venting-induced elevated moisture layers in the lee of the Alps, J. Appl. Meteorology, 44, 620-633, 2005.

Henne, S., Klausen, J., Junkermann, W., Kariuki, J. M., Aseyo, J. O., and Buchmann, B.: Representativeness and climatology of carbon monoxide and ozone at the global GAW station Mt. Kenya in equatorial Africa, Atmos. Chem. Phys., 8, 3119-3139, doi:10.5194/acp-8-3119-2008, 2008.

Hirdman, D., Sodemann, H., Eckhardt, S., Burkhart, J. F., Jefferson, A., Mefford, T., Quinn, P. K., Sharma, S., Ström, J., and Stohl, A.: Source identification of short-lived air pollutants in the Arctic using statistical analysis of measurement data and particle dispersion model output, Atmos. Chem. Phys., 10, 669-693, doi:10.5194/acp-10-669-2010, 2010.

Holloway, T., Levy, H., and Kasibhatla, P.: Global distribution of carbon monoxide, J. Geophys. Res., 105, 12123-12147, 2000.

Jacob, D. J.: Introduction to Atmospheric Chemistry, Princeton University Press, Princeton New Jersey, 1999.

Maronna, A., Martin, R., and Yohai, V.: Robust Statistics: Theory and Methods, Wiley Series in Probability and Statistics, John Wiley and Sons Ltd., Chichester, UK, 2006.

Miller, B. R., Weiss, R. F., Salameh, P. K., Tanhua, T., Greally, B. R., Mühle, J., and Simmonds, P. G.: Medusa: A sample preconcentration and GC/MS detector system for in situ measurements of atmospheric trace halocarbons, hydrocarbons, and sulfur compounds, Anal. Chem., 80, 1536-1545, doi:10.1021/ac702084k, 2008.

Novelli, P., Masarie, K., and Lang, P.: Distributions and recent changes of carbon monoxide in the lower troposphere, J. Geophys. Res., 103, 19015-19033, 1998.

Novelli, P., Masarie, K., Lang, P., Hall, B., Myers, R., and Elkins, J.: Reanalysis of tropospheric CO trends: Effect of the 1997-1998 wildfires, J. Geophys. Res., 108, 4464, doi:10.1029/2002JD003031,031, 2003.

O’Doherty, S., Simmonds, P., Cunnold, D., Wang, H., Sturrock, G., Fraser, P., Ryall, D., Derwent, R., Weiss, R., Salameh, P., Miller, B., and Prinn, R.: In situ chloroform measurements at Advanced Global Atmospheric Gases Experiment atmospheric research stations from 1994 to 1998, J. Geophys. Res., 106, 20429-20444, 2001.

Prinn, R. G., Huang, J., Weiss, R. F., Cunnold, D. M., Fraser, P. J., Simmonds, P. G., McCulloch, A., Harth, C., Salameh, P., O’Doherty, S., Wang, R. H. J., Porter, L., and Miller, B. R.: Evidence for substantial variations of atmospheric hydroxyl radicals in the past two decades, Science, 292, 1882-1888, 2001.

R Development Core Team: R: A language and environment for statistical computing, R Foundation for Statistical Computing, Vienna, Austria, available at: http://www.R-project.org (last access: 13 July 2012), ISBN 3-900051-07-0, 2009.

Reimann, S., Manning, A. J., Simmonds, P. G., Cunnold, D. M., Wang, R. H. J., Li, J., McCulloch, A., Prinn, R. G., Huang, J., Weiss, R. F., Fraser, P. J., O’Doherty, S., Greally, B. R., Stemmler, K., Hill, M., and Folini, D.: Low European methyl chloroform emissions inferred from long-term atmospheric measurements, Nature, 433, 506-508, 2005.

Reimann, S., Vollmer, M. K., Folini, D., Steinbacher, M., Hill, M., Buchmann, B., Zander, R., and Mahieu, E.: Observations of long-lived anthropogenic halocarbons at the highAlpine site of Jungfraujoch (Switzerland) for assessment of trends and European sources, Sci. Total Environ., 391, 224-231, doi:10.1016/j.scitotenv.2007.10.022, 2008.

Ruckstuhl, A. F., Jacobson, M. P., Field, R. W., and Dodd, J. A.: Baseline Subtraction Using Robust Local Regression Estimation, J. Quant. Spectrosc. Ra., 68, 179-193, 2001.

Ruckstuhl, A. F., Unternaehrer, T., and Locher, R.: IDPmisc: Utilities of Institute of Data Analyses and Process Design (www. idp.zhaw.ch), available at: http://CRAN.R-project.org/package= IDPmisc (last access: 13 July 2012), R package version 1.1.06, 2009.

Ryall, D. B., Maryon, R. H., Derwent, R. G., and Simmonds, P. G.: Modelling long-range transport of CFCs to Hace Head, Ireland, Q. J. Roy. Meteorol. Soc., 124, 417-446, 1998.

Ryall, D. B., Derwent, R., Manning, A., Simmonds, P., and O'Doherty, S.: Estimating source regions of European emissions of trace gases from observations at Mace Head, Atmos. Environ., 35, 2507-2523, doi:10.1016/S1352-2310(00)00433-7, 2001.

Salibian-Barrera, M. and Zamar, R. H.: Bootstrapping Robust Estimates of Regression, The Annals of Statistics, 30, 556-582, 2002.

Schuepbach, E., Friedli, T., Zanis, P., Monks, P., and Penkett, S.: State space analysis of changing seasonal ozone cycles (19881997) at Jungfraujoch (3580 m above sea level) in Switzerland, J. Geophys. Res., 106, 20413-20427, 2001.

Simmonds, P. G., O’Doherty, S., Nickless, G., Sturrock, G. A., Swaby, R., Knight, P., Ricketts, J., Woffendin, G., and Smith, R.: Automated Gas Chromatograph Mass Spectrometer For Routine Atmospheric Field Measurements of the CFC Replacement Compounds, the hydrofluorocarbons and hydrochlorofluorocarbons, Anal. Chem., 67, 717-723, 1995.

Simmonds, P. G., Manning, A., Cunnold, D., McCulloch, A., O’Doherty, S., Derwent, R., Krummel, P., Fraser, P., Dunse, B., 
Porter, L., Wang, R., Greally, B., Miller, B., Salameh, P., Weiss, R., and Prinn, R.: Global trends, seasonal cycles, and European emissions of dichloromethane, trichloroethene from the AGAGE observations at Mace Head, Ireland, and Cape Grim, Tasmania, J. Geophys. Res., 111, D18304, doi:10.1029/2006JD007082, 2001.

Simonoff, J. S.: Smoothing Methods in Statistics, Springer Series in Statistics, Springer-Verlag New York, 1996.

Thoning, K., Tans, P., and Komhyr, W.: Atmospheric Carbon Dioxide at Mauna Loa Observatory. 2. Analysis of the NOAA GMCC Data, 1974-1985, J. Geophys. Res., 94, 8549-8565, 1989.

Yurganov, L. N., Duchatelet, P., Dzhola, A. V., Edwards, D. P., Hase, F., Kramer, I., Mahieu, E., Mellqvist, J., Notholt, J., Novelli, P. C., Rockmann, A., Scheel, H. E., Schneider, M., Schulz, A., Strandberg, A., Sussmann, R., Tanimoto, H., Velazco, V., Drummond, J. R., and Gille, J. C.: Increased Northern Hemispheric carbon monoxide burden in the troposphere in 2002 and 2003 detected from the ground and from space, Atmos. Chem. Phys., 5, 563-573, doi:10.5194/acp-5-563-2005, 2005.
Zanis, P., Ganser, A., Zellweger, C., Henne, S., Steinbacher, M., and Staehelin, J.: Seasonal variability of measured ozone production efficiencies in the lower free troposphere of Central Europe, Atmos. Chem. Phys., 7, 223-236, doi:10.5194/acp-7-223-2007, 2007.

Zellweger, C., Ammann, M., Buchmann, B., Hofer, P., Lugauer, M., Rüttimann, R., Streit, N., Weingartner, E., and Baltensperger, U.: Summertime $\mathrm{NO}_{\mathrm{y}}$ speciation at the Jungfraujoch, $3580 \mathrm{~m}$ above sea level, Switzerland, J. Geophys. Res., 105, 6655-6667, 2000.

Zellweger, C., Forrer, J., Hofer, P., Nyeki, S., Schwarzenbach, B., Weingartner, E., Ammann, M., and Baltensperger, U.: Partitioning of reactive nitrogen $\left(\mathrm{NO}_{\mathrm{y}}\right)$ and dependence on meteorological conditions in the lower free troposphere, Atmos. Chem. Phys., 3, 779-796, doi:10.5194/acp-3-779-2003, 2003.

Zellweger, C., Hüglin, C., Klausen, J., Steinbacher, M., Vollmer, M., and Buchmann, B.: Inter-comparison of four different carbon monoxide measurement techniques and evaluation of the long-term carbon monoxide time series of Jungfraujoch, Atmos. Chem. Phys., 9, 3491-3503, doi:10.5194/acp-9-3491-2009, 2009. 